\title{
Trends in, and determinants of, HIV testing at genitourinary medicine clinics and general practice in England, 1990- 2000
}

\author{
T R Chadborn, C A McGarrigle, P A Waight, K A Fenton, on behalf of the HIV Testing Surveillance \\ Collaborative Group
}

Sex Transm Infect 2004;80:145-150. doi: 10.1136/sti.2003.006288

See end of article for authors' affiliations

.....................

Correspondence to:

Tim Chadborn, HIV/STI

Department,

Communicable Disease

Surveillance Centre, 61

Colindale Avenue, London

NW9 5EQ, UK;

tim.chadborn@hpa.org.uk

Accepted for publication 5 November 2003

\begin{abstract}
Objectives: To describe the trends in and determinants of HIV testing and positivity at genitourinary medicine (GUM) clinics and in general practice (GP) in England between 1990 and 2000.

Methods: Data on all first HIV specimens from GUM and GP clinics and tested at seven sentinel laboratories were related to key demographic, clinical, and behavioural variables.

Results: During the observation period, 202892 eligible first HIV tests were reported. 90\% (182 746) of specimens were from GUM clinics, of which $55 \%$ were from heterosexuals, $12 \%$ from men who have sex with men (MSM), and 3\% from injecting drug users (IDU). In contrast, only 3\% of GP specimens were from MSM and 13\% from IDUs. The total number of first HIV tests increased threefold between 1990 and 2000. Overall, $1.6 \%$ of GUM and $0.9 \%$ of GP first testers were diagnosed HIV positive. In GUM clinics, HIV positivity was highest among heterosexuals who have lived in Africa (11.7\%), MSM (6.9\%), and IDUs $(2.8 \%)$ and lowest among heterosexuals with no other specified risk $(0.3 \%)$. Consistently lower prevalences were observed in GP settings. HIV positivity among GUM first testers declined in MSM, from $13.6 \%$ in 1990 to $5.2 \%$ in $2000(p<0.01)$, and in IDUs, from $7.5 \%$ in 1990 to $2.0 \%$ in $2000(p=0.03)$. Prevalence remained constant in the groups heterosexually exposed to HIV infection.

Conclusions: HIV testing in GUM settings increased over the decade, with a concomitant reduction in HIV positivity among MSM and IDUs. Increased testing among heterosexual first testers overall was not associated with declining positivity.
\end{abstract}

$B$ $y$ the end of June 2002, over 4400 HIV infections newly diagnosed in the United Kingdom in 2001 had been reported to the Communicable Disease Surveillance Centre (CDSC) with 26635 HIV infected individuals reported as being seen for care during that year in the United Kingdom. ${ }^{1}$ Two decades of intensive HIV health promotion have seen gradual and sustained increases in HIV testing among GUM attendees in the United Kingdom. Statutory returns made by GUM clinics in England (form KC60) show that the number of episodes of HIV counselling and testing increased by $35 \%$ in the last year, $56 \%$ in the past 3 years, and by $90 \%$ in the past 6 years to 201347 in $2001 .^{2}$ Nevertheless, substantial numbers of HIV infected individuals in the United Kingdom still do not know their HIV status ${ }^{3}$ and therefore cannot receive appropriate care, notify their partners, or be guided in safer sexual behaviour in knowledge of their status. ${ }^{4}$

In an effort to reduce the number of undiagnosed HIV infections in the population and to reduce HIV transmission, testing promotion has been prioritised by the Department of Health's National Strategy for Sexual Health and HIV for England. ${ }^{5}$ Key strategies include the provision of clear information to the public about HIV with the aim of encouraging the demand for voluntary HIV testing while improving access to GUM services and increasing the offer of HIV testing. At the same time, there is a growing acknowledgement of the need to remove the exceptionalism and stigma associated with HIV testing by providing these services outside traditional GUM and antenatal settings. ${ }^{6}$ Currently, there is little information on HIV testing trends in general practice in England ${ }^{7}$ or in other settings where individuals at increased risk may be seen (for example, termination of pregnancy clinics).
This study aimed to explore trends in HIV testing in GUM clinics and the comparative trends in GP practices using data derived from an existing sentinel laboratory surveillance programme. $^{8}$ In this paper we focus on changes in HIV testing over time by exposure category and sex, and compare the numbers of HIV tests and HIV positivity across risk groups.

\section{METHODS}

Study description

The denominator study was set up in 1986 by the Public Health Laboratory Service (PHLS) to monitor trends and determinants of voluntary HIV testing in England through the sentinel surveillance of 18 laboratories. ${ }^{8}$ Seven sentinel laboratories in England (three in London and four outside London) were selected to continue after 1998 on the basis of their ability to provide complete electronic records of their HIV tests to Communicable Disease Surveillance Centre (CDSC). They were not a randomly selected sample of laboratories and cannot be assumed to reflect all HIV testing in England. However, these sentinel laboratories accounted for $16 \%$ of all HIV tests reported from English GUM clinics in 2000 and areas outside London were well represented. All laboratories participated in a national external quality assurance scheme for HIV (NEQAS). There is no evidence to suggest that any differences in the sensitivity of HIV tests for different subtypes would have a significant effect on detected HIV positivity between exposure categories or over time. ${ }^{9}$ Enhanced epidemiological data on exposure, reasons for testing, and HIV related symptoms at the time of test have been routinely collected at these centres on all HIV test request forms, which collected the same core dataset. 
Variations between sites were accommodated by regrouping data into broader categories for this analysis.

\section{Data extraction}

First tests of individuals were identified on each laboratory database in the laboratory by matching on either GUM number or name and date of birth. All patient identifiers were then removed before extracts of all first tests were sent to CDSC for addition to a central database. Variables collected on each patient included date and final result of test, source of specimen, age, sex, reported risk factors, nature of contact involved in the HIV transmission risk, reasons for testing, and symptoms at the time of test. Specimens referred to participating laboratories from other laboratories for confirmatory testing were excluded.

\section{Data preparation}

For this analysis all first HIV tests performed between 1 January 1990 and 31 December 2000 in the seven sentinel sites were selected. HIV tests from hospital wards and other clinics were excluded leaving only those tests requested by GUM clinics and GPs. We excluded individuals recorded as known to be HIV positive (because this would not have been their first test), those with unknown or equivocal test results, and people aged less than 15 or of unknown age. We also excluded individuals whose HIV test was clearly prompted by some other reason than a perception of HIV risk: pregnant women, organ/tissue donors, and individuals with either antiretroviral treatment or special survey reported as the reason for their test. Exposure categories were assigned to the individuals tested according to their reported risk factors and the nature of contact through which HIV may have been transmitted. This allocation used a hierarchical algorithm (fig 1): men who have sex with men (MSM); injecting drug users (IDU); recipients of blood/blood products or tissues (Blood); heterosexuals with high risk partners (HET HRP); heterosexuals who have lived in Africa (HET LA); heterosexuals with no other specified risk (HET OT). Those with no identified risk behaviour and those with other risk behaviours reported were grouped as such. For each centre, data were checked for evidence of inconsistent data entry. This identified HIV tests for which the source of test had been systematically misclassified over a period of time at one laboratory. Tests were reallocated to the GUM clinic.

\section{Statistical analysis}

Stata 7.0 software was used for statistical analyses of the data. Differences in proportions were tested by Pearson's $\chi^{2}$ method and Fisher's exact test where appropriate. Point estimates and exact confidence intervals for odds ratios were calculated for comparison of the odds of testing positive by exposure, source, and sex. Trends were analysed using linear regression using ordinary least squares.

\section{RESULTS}

\section{Overall description of sample}

A total of 206782 first HIV specimens were tested at the seven sentinel sites over the 10 year period; $98 \%$ were eligible for inclusion in this study. Two laboratories, both in London and with more than 50000 tests each, accounted for over $50 \%$ of the tests. Ninety per cent (182 746/202 892) of the eligible tests were requested from GUM clinics. The majority of tests $(77 \%)$ were performed on samples from heterosexuals with no other specified risk and individuals with no identified risk ( $50 \%$ and $28 \%$ respectively at GUM clinics and $17 \%$ and $56 \%$ respectively at GPs). MSM accounted for $11.2 \%$ (22 685/202 892) of individuals tested for HIV, with the proportion ranging from $3.8 \%(522 / 13817)$ to $19.5 \%$ (11 111 / 56 916) across sites.

\section{HIV testing by source of specimen}

More first HIV tests from GUM clinics than from GPs were reported in each exposure category, both within and outside London (table 1). Overall, in GUM clinics 12\% of HIV tests were for MSM and only 3\% for IDUs. In contrast, 3\% of tests requested by GPs were for MSM and 13\% for IDUs. Overall, a higher proportion of individuals tested at GUM clinics (55\%) were heterosexuals than those tested at GPs $(22 \%)(\mathrm{p}<0.01)$. In contrast, individuals with no identified risk accounted for $28 \%$ of the individuals tested at GUM clinics and $56 \%$ of those tested at GP $(\mathrm{p}<0.01)$.

Significant sex differences in HIV testing were observed between exposure categories. Females accounted for over $70 \%$ (4082 of 5164 overall) of heterosexuals with high risk partners in both GUM clinics and at GP practices, both within

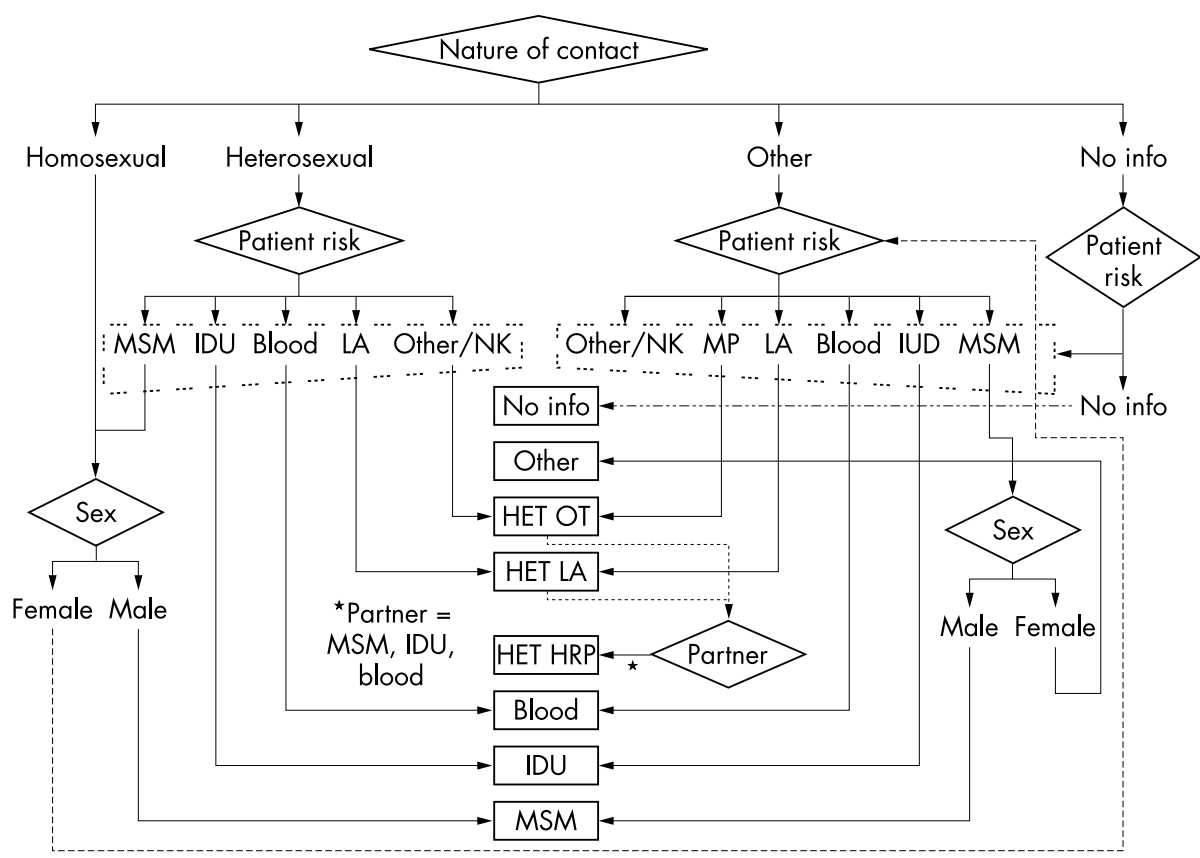

Figure 1 Algorithm for the hierarchical categorisation of exposures. The patient risk has decreasing hierarchy from MSM to Other/NK. MSM = men who have sex with men, IDU = injecting drug user, Blood = haemophiliac or transfusion/ transplant recipient, $M P=$ multiple heterosexual partners, HET =

heterosexual, OT $=$ no other specified risk, LA = lived in Africa, HRP = high risk partner. 
Table 1 Number and percentage of HIV tests by source and exposure category*

\begin{tabular}{|c|c|c|c|c|}
\hline \multirow[b]{2}{*}{ Exposure category } & \multicolumn{2}{|l|}{ London } & \multicolumn{2}{|c|}{ Outside London } \\
\hline & GP total (\%) & GUM total (\%) & GP total (\%) & GUM total (\%) \\
\hline Sex between men & $141(2)$ & 13734 (15) & $520(4)$ & 8290 (9) \\
\hline Injecting drug use & 981 (15) & $2273(3)$ & 1556 (11) & 2408 (3) \\
\hline Blood or tissues & $33(1)$ & $352(0)$ & $114(1)$ & $303(0)$ \\
\hline \multicolumn{5}{|l|}{ Heterosexual: } \\
\hline High risk partner & $89(1)$ & $2196(2)$ & $430(3)$ & $2470(3)$ \\
\hline Lived in Africa & $146(2)$ & 3642 (4) & $254(2)$ & 1008 (1) \\
\hline Other & $660(10)$ & $41744(46)$ & $2829(21)$ & 49669 (54) \\
\hline No identified risk & $3887(61)$ & $25419(28)$ & 7310 (53) & $25645(28)$ \\
\hline Other risk & $479(8)$ & $1619(2)$ & $717(5)$ & $1974(2)$ \\
\hline Total & $6416(100)$ & $90979(100)$ & $13730(100)$ & $91767(100)$ \\
\hline
\end{tabular}

and outside London (table 2), but $30 \%$ or less of tested IDUs at all sources (data not shown). Among heterosexuals who have lived in Africa, men accounted for 61\% (609 of 1003) of tests at GUM clinics and 69\% (176 of 254) of tests at GPs outside London (with a more even balance in London).

The overall modal age group for each exposure category was 25-29 years of age except for the female heterosexuals with high risk partners who were generally younger (table 2). MSM and IDUs tested outside London were younger than those tested in London. Male heterosexuals with no other specified risk were younger than females except at GUM clinics within London.

\section{Trends in HIV testing}

The annual number of first tests increased from 8328 in 1990 to 26389 in 2000 . There was a linear increase from 1996 to $2000(p<0.01)$ averaging 1932 tests per year. The total contribution of HIV tests from GUM clinics increased from 6398 in 1990 to 23923 in $2000(\mathrm{p}<0.01)$. There was no significant linear change in the total number of tests at GPs ( 1930 in 1990 to 2466 in 2000, $\mathrm{p}=0.58$ ).

At GUM clinics, HIV tests increased from all exposure groups except heterosexuals with high risk partners, the recipients of blood/blood products or tissues and those with other risk behaviours. Heterosexuals with no other specified

Table 2 Distribution of HIV prevalence within exposure categories by source and region

\begin{tabular}{|c|c|c|c|c|c|c|c|}
\hline & \multicolumn{3}{|l|}{ London } & \multicolumn{3}{|c|}{ Outside London } & \multirow[b]{2}{*}{ Total } \\
\hline & GP & GUM & $\mathrm{OR}^{*}(95 \% \mathrm{Cl})$ & GP & GUM & $\mathrm{OR}^{*}(95 \% \mathrm{Cl})$ & \\
\hline \multicolumn{8}{|c|}{ Homosexual and bisexual men } \\
\hline Total number tested & 141 & 13734 & \multirow{3}{*}{$1.98(1.20-3.16)$} & 520 & 8290 & \multirow{3}{*}{0.89 (0.53 to 1.44$)$} & 22685 \\
\hline HIV prevalence & $15.6 \%$ & $8.5 \%$ & & $3.7 \%$ & $4.1 \%$ & & $6.8 \%$ \\
\hline Modal age group & $25-29$ & $25-29$ & & $20-24$ & $20-24$ & & $25-29$ \\
\hline Total number tested & 981 & 2273 & \multirow{4}{*}{0.29 (0.15 to 0.52$)$} & 1556 & 2408 & \multirow{4}{*}{$0.38(0.15$ to 0.85$)$} & 7175 \\
\hline HIV prevalence & $1.3 \%$ & $4.4 \%$ & & $0.5 \%$ & $1.3 \%$ & & $2.1 \%$ \\
\hline Modal age group & $30-34$ & $25-29$ & & $20-24$ & $20-24$ & & $25-29$ \\
\hline \multicolumn{6}{|l|}{ Female heterosexuals: } & & \\
\hline Total number tested (\%) & $472(100)$ & $26289(100)$ & \multirow{4}{*}{1.64 (0.83 to 2.92$)$} & $1654(100)$ & $26670(100)$ & \multirow{4}{*}{$1.45(0.56$ to 3.14$)$} & $55085(100)$ \\
\hline HIV prevalence & $2.5 \%$ & $1.6 \%$ & & $0.4 \%$ & $0.3 \%$ & & $0.9 \%$ \\
\hline Modal age group & $20-24$ & $20-24$ & & $20-24$ & $20-24$ & & $20-24$ \\
\hline \multicolumn{6}{|l|}{ High risk partner } & & \\
\hline Total number tested (\%) & $74(16)$ & $1740(7)$ & \multirow{3}{*}{$\mathrm{n} / \mathrm{a}$} & 311 (19) & 1957 (7) & \multirow{3}{*}{$\mathrm{n} / \mathrm{a}$} & $4082(7)$ \\
\hline HIV prevalence & $0.0 \%$ & $0.6 \%$ & & $0.0 \%$ & $0.2 \%$ & & $0.3 \%$ \\
\hline Modal age group & $20-24$ & $25-29$ & & $25-29$ & $20-24$ & & $20-24$ \\
\hline \multicolumn{8}{|l|}{ Lived in Africa } \\
\hline Total number tested (\%) & $65(14)$ & 1754 (7) & \multirow{4}{*}{$1.06(0.50-2.09)$} & $78(5)$ & $394(1)$ & \multirow{4}{*}{0.83 (0.28 to 2.09$)$} & $2291(4)$ \\
\hline HIV prevalence & $16.9 \%$ & $16.1 \%$ & & $7.7 \%$ & $9.1 \%$ & & $14.6 \%$ \\
\hline Modal age group & $25-29$ & $25-29$ & & $25-29$ & $25-29$ & & $25-29$ \\
\hline \multicolumn{6}{|l|}{ Other } & & \\
\hline Total number tested (\%) & $333(71)$ & 22795 (87) & \multirow{4}{*}{$0.57(0.01$ to 3.25$)$} & $1265(76)$ & $24319(91)$ & \multirow{4}{*}{$0.49(0.01$ to 2.92$)$} & $48712(88)$ \\
\hline HIV prevalence & $0.3 \%$ & $0.5 \%$ & & $0.1 \%$ & $0.2 \%$ & & $0.3 \%$ \\
\hline Modal age group & $25-29$ & $25-29$ & & $25-29$ & $25-29$ & & $25-29$ \\
\hline \multicolumn{6}{|l|}{ Male heterosexuals: } & & \\
\hline Total number tested (\%) & $399(100)$ & $21129(100)$ & \multirow{4}{*}{$2.71(1.48$ to 4.60$)$} & $1854(100)$ & $26340(100)$ & \multirow{4}{*}{$0.68(0.18$ to 1.80$)$} & $49722(100)$ \\
\hline HIV prevalence & $3.8 \%$ & $1.4 \%$ & & $0.2 \%$ & $0.3 \%$ & & $0.8 \%$ \\
\hline Modal age group & $25-29$ & $25-29$ & & $20-24$ & $20-24$ & & $25-29$ \\
\hline \multicolumn{6}{|l|}{ High risk partner } & & \\
\hline Total number tested (\%) & $13(3)$ & $446(2)$ & \multirow{4}{*}{$\mathrm{n} / \mathrm{a}$} & $118(6)$ & $505(2)$ & & $1082(2)$ \\
\hline HIV prevalence & $0.0 \%$ & $1.6 \%$ & & $0.0 \%$ & $0.6 \%$ & $\mathrm{n} / \mathrm{a}$ & $0.9 \%$ \\
\hline Modal age group & $25-29$ & $25-29$ & & $25-29$ & $20-24$ & & $25-29$ \\
\hline Lived in Africa & & & & & & & \\
\hline Total number tested (\%) & 76 (19) & 1869 (9) & & $176(9)$ & 609 (2) & & $2730(5)$ \\
\hline HIV prevalence & $13.2 \%$ & $10.0 \%$ & 1.37 (0.62 to 2.74$)$ & $1.7 \%$ & $6.2 \%$ & 0.26 (0.05 to 0.84$)$ & $8.7 \%$ \\
\hline Modal age group & $25-29$ & $25-29$ & & $35-39$ & $25-29$ & & $25-29$ \\
\hline Other & & & & & & & \\
\hline Total number tested (\%) & $310(78)$ & 18814 (89) & & $1560(84)$ & $25226(96)$ & & $45910(92)$ \\
\hline HIV prevalence & $1.6 \%$ & $0.6 \%$ & 2.87 (0.91 to 6.97$)$ & $0.1 \%$ & $0.2 \%$ & $0.38(0.01$ to 2.21$)$ & $0.3 \%$ \\
\hline Modal age group & $20-24$ & $25-29$ & & $20-24$ & $20-24$ & & $25-29$ \\
\hline
\end{tabular}



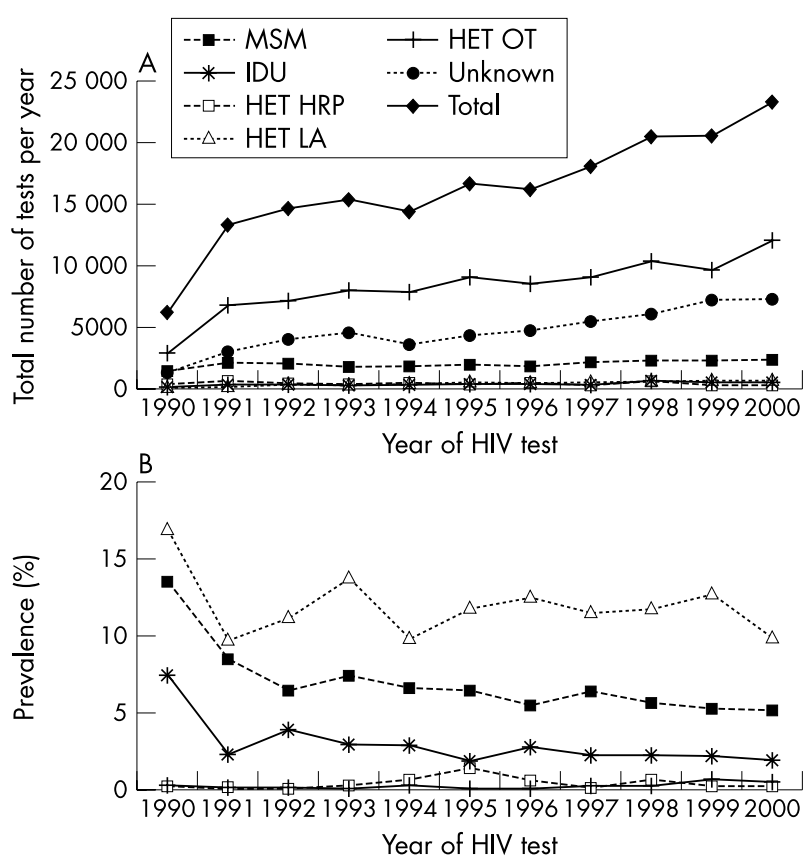

Figure 2 Trends in (A) HIV testing and (B) HIV prevalence among first testers at GUM clinics. MSM = men who have sex with men; IDU = injecting drug users; HET HRP = heterosexuals with high risk partners; HET LA = heterosexuals who have lived in Africa; HET OT = heterosexuals with no other specified risk; Unknown = no identified risk reported.

risk and people with no identified risk accounted for most of the overall increase (fig 2A). Consequently, the proportion of HIV tests among MSM declined from 23\% in 1990 to $10 \%$ in $2000(\mathrm{p}=0.01)$, from $4 \%$ to $2 \%(\mathrm{p}=0.02)$ among IDUs, and from $5 \%$ to $1 \%(p=0.00)$ among heterosexuals with high risk partners.

At GPs, the proportion of tests requested by IDUs increased over time $(4 \%(84 / 1930)$ in 1990 to $21 \%(524 / 2466)$ in 2000 , $\mathrm{p}<0.01$ ), which contributed to the gradual declines in the proportion of tests requested from MSM $(p<0.01)$, heterosexuals with high risk partners $(\mathrm{p}<0.01)$, heterosexuals who have lived in Africa $(p=0.02)$, and heterosexuals with no other specified risk $(\mathrm{p}<0.01)$.

\section{HIV prevalence}

Marked geographic heterogeneity in HIV positivity was observed in those being tested for the first time. Sites in London had generally higher positivity than those outside $(2.6 \%$ compared to $0.7 \%, \mathrm{p}<0.01)$. At GUM clinics, HIV prevalence was generally significantly higher in all exposure categories in London compared to outside London (table 2). This was also the case at GPs except where the numbers tested or the numbers tested positive were small.

Overall, HIV positivity was high in heterosexuals who have lived in Africa (11.4\%, 572 of 5021), in MSM (6.8\%, 1550 of 22685 ) and in recipients of blood/blood products or tissues $(4.3 \%, 34$ of 794 ). HIV positivity was $0.4 \%$ (23 of 5164 ) in heterosexuals with high risk partners and $0.3 \%$ (317 of 94622 ) in heterosexuals with no other specified risk. HIV positivity in female heterosexuals who have lived in Africa was higher overall than that in males in the same exposure category ( $14.6 \%$ v 8.7\%; odds ratio (OR) 1.80 (95\% CI 1.50 to 2.16)) (table 2). This contrasts with a higher prevalence in male heterosexuals with high risk partners than in females $(0.9 \% v 0.3 \%$, OR 2.92 ( 1.14 to 7.23$))$.

Within London, HIV positivity was higher among MSM tested at GPs than in those tested at GUM clinics (15.6\% v
$8.5 \%$, OR 1.98 ( 1.20 to 3.16 )). A similar difference was weakly significant for male heterosexuals with no other specified risk ( $1.6 \% v 0.6 \%$, OR 2.87 (0.91 to 6.97)). In contrast, prevalence was lower among IDUs tested at GPs than at GUM clinics ( $1.4 \% v 4.4 \%$, OR $0.30(0.15$ to 0.54$)$ ). HIV positivity was also lower at GPs than at GUM clincs outside London among IDUs and among male heterosexuals who have lived in Africa $(0.5 \% v 1.3 \%$, OR 0.38 ( 0.15 to 0.85$)$ and $1.7 \% v 6.2 \%$, OR 0.26 (0.05 to 0.84 ) respectively).

\section{Trends in HIV prevalence at GUM clinics}

Linear regression analysis in MSM showed significant decreases in HIV prevalence over time overall $(\mathrm{p}<0.01)$ (fig $2 \mathrm{~B}$ ) and both within London $(\mathrm{p}<0.01)$ and outside London $(p=0.02)$. A significant decline was also seen for IDUs tested in London $(p=0.02)$ but there was no evidence of a decline outside London $(\mathrm{p}=0.22)$. No other strongly significant trends were observed. However, HIV prevalence among heterosexuals with no other specified risk decreased from $0.43 \%$ in 1990 to $0.16 \%$ in 1996 and then increased to $0.57 \%$ in 2000 . Similar trends were seen in both heterosexual males and females, both within and outside London. The numbers of individuals first tested at GPs in each year were not large enough for analysis of trends within exposure groups.

\section{DISCUSSION}

Between 1990 and 2000 the number of voluntary HIV tests undertaken at these seven sentinel sites more than tripled. GUM clinics accounted for the majority of this increase with a near quadrupling of tests while little overall change was seen in the number of HIV tests undertaken at GPs. The increased HIV testing at GUM clinics was observed among all exposure groups except heterosexuals with high risk partners and occurred over a period when new attendances at these sites doubled..$^{10}$ Our data confirm that much of the increase was due to testing among low risk heterosexuals. This may have been a direct response to sexual health promotion messages throughout the 1990s although other factors such as changing clinic policies regarding the offer of routine HIV testing may also have contributed. ${ }^{11}$

Trends in HIV positivity among first time testers varied considerably by exposure category. The HIV positivity among heterosexuals who have lived in Africa (11.4\%) and among MSM $(6.8 \%)$ in our study were similar to those found among testers attending a same day testing service at a large inner London hospital in $2000-1^{12}$ (11.2\% and $6.2 \%$ respectively), although the positivity found there among low risk heterosexuals ( $1.8 \%$ in males and $1.4 \%$ in females) were much higher than in our study. Our study suggests that equivalent numbers of heterosexual men and women who have lived in Africa were tested for HIV in England during the past decade, consistent with other community based studies in England. ${ }^{13}$ Despite this, our study documents a significantly lower HIV positivity among males who have lived in Africa compared with females and may help to explain why men account for less than $40 \%$ of black Africans reported to the national surveillance scheme of newly diagnosed HIV patients since $1995 .^{1}$

The data provide evidence of a continual decline in HIV prevalence among MSM and IDU first testers at GUM clinics between 1990 and 2000. This could not be accounted for by changes in the age distribution of first testers and trends in HIV prevalence were similar in all age groups. Decreasing trends in HIV prevalence in the United Kingdom have been reported among male homosexual and bisexual GUM clinic attenders tested for syphilis between 1993 and 2000 that were not previously diagnosed with HIV in the unlinked anonymous seroprevalence surveys. ${ }^{4}$ Similar trends among 
GUM clinic attenders have been found in Amsterdam (first testers) ${ }^{14}$ and America (all testers), ${ }^{15}$ where declines in HIV prevalence among MSM and IDU contrast with stable prevalence among heterosexuals and those with no identified risk.

Our study has limitations. In this study we focused on positivity as a proxy for prevalence, and therefore cannot infer incidence or changes in incidence. It has previously been suggested that a decrease in prevalence can mask stable or increasing incidence, ${ }^{16}$ evident from studies in the Netherlands, ${ }^{17}$ the United States, ${ }^{15}$ and England..$^{18}$

There was marked heterogeneity among the seven participating laboratories in terms of case mix and prevalence. This will be masked by their aggregation into London and outside London regions. The heterogeneity is most evident in the analysis of trends in the numbers HIV testing at GPs.

There is limited information from this study about variations in HIV prevalence according to behavioural risk. In particular, identification of repeat testers as a proxy for high risk behaviour would have provided further classification of exposure categories but was not available in this study of first HIV tests.

Matching HIV tests using identical clinic number or identical name and date of birth to identify the first test of individuals cannot completely identify all repeat tests on all individuals. This may have allowed HIV tests that were not the first test of the individual to have been included in the analysis. Also, the hierarchical classification of HIV exposure categories is intended to assign patients the "exposure of greatest risk" if multiple risk behaviours have been reported. This will tend to oversimplify patients' exposures but similar assumptions have been made in other HIV surveillance systems. ${ }^{19}$

Finally, the classification of exposure categories was incomplete, as patient HIV exposure information was not fully available from GUM clinics or GPs. Failure to complete forms could have led to misclassification bias, as exposures may be less likely to be reported in the absence of high risk behaviours. This may have led to overestimation of prevalence in each exposure category and underestimation of the number of heterosexuals tested. There was a low prevalence among those with no identified risk $(0.9 \%$ males, $0.4 \%$ females), which suggests the majority were heterosexuals with no other specified risk.

The results of our paper will nevertheless be of interest to those involved in sexual health policy. The English National Strategy for Sexual Health and HIV has prioritised the uptake of HIV testing as a core HIV prevention intervention with two main aims. ${ }^{5}$ The first is to reduce the number of HIV infected individuals who remain undiagnosed after attending a GUM clinic. The second is to encourage HIV testing of people at a wider range of sites including primary care and general medical settings. ${ }^{5}$ Ongoing surveillance of HIV testing as outlined in this paper will provide a key mechanism for monitoring progress on these goals. Alongside increased offers of HIV testing, this analysis supports the need for targeting groups at high risk of HIV infection with HIV testing interventions, including MSM, IDU, and adults who have had heterosexual contact in Africa. Such focused promotion of HIV testing will be more cost effective than testing of individuals at lower risk, as fewer HIV tests are needed to diagnose one HIV infection. However, it is estimated that nearly twice as many HIV infected heterosexuals were living with undiagnosed HIV as homosexual or bisexual men at the end of $2001^{1}$ and it is known that a large proportion of heterosexuals were not diagnosed until late in the course of infection between 1990 and 2000 in England. ${ }^{20}$ The strategy for sexual health addresses these issues through targeted campaigns to encourage the uptake of HIV testing in high risk groups and policies to increase the offer of HIV tests at healthcare sites, which should also capture heterosexual individuals with high risk behaviours. However, it should be acknowledged that GUM clinics will need to be supported as promotion of HIV testing further adds to their workload.

\section{ACKNOWLEDGEMENTS}

We thank the following collaborators for their support and participation in the project: MS Shafi, P Pandya, and B Patel at Central Middlesex Public Health Laboratory (PHL); RS Tedder and P Luton at University College Hospital; GJ Pinney, J Sellwood, and C Woods at Reading PHL; J Mowbray, A Guest, and S Skidmore at Birmingham PHL; M Zuckerman, T Leung, D Johnson, and M Hopper at Dulwich PHL; P Parker at Exeter PHL; C Ashley at Bristol PHL.

We also gratefully acknowledge the continuing collaboration of clinicians, microbiologists, health advisers, and everyone else at GUM clinics and GPs who contributed to HIV testing surveillance at the sentinel sites.

\section{CONTRIBUTORS}

TRC was the main author and current project coordinator: responsible for recent data collection, data analysis, report drafting, and editing; CAM contributed to scientific interpretation of data, the critique and revision of drafts, and was involved in the approval of the final version of the submitted paper; PAW was responsible for the conception and design of the study and the majority of data collection: also helped with the critique and the revision and approval of the paper; KAF was responsible for final approval of paper, contributed significantly to the scientific interpretation of data, and the critique and revised draft versions.

\section{Authors' affiliations}

T R Chadborn, C A McGarrigle, P A Waight, K A Fenton, HIV/STI

Division, Communicable Disease Surveillance Centre, Health Protection Agency, 61 Colindale Avenue, London NW9 5EQ, UK

K A Fenton, Department of STDs, Royal Free and University College London Medical School, off Capper Street, London WC1E 6AU, UK

Conflict of interest: None

\section{REFERENCES}

1 PHLS Communicable Disease Surveillance Centre, ICH (London), SCIEH. HIV \& AIDS in the United Kingdom 2001: an update November 2002. London: Public Health Laboratory Service, 2002.

2 PHLS, DHSS\&PS, and the Scottish ISD(D) 5 Collaborative group. Sexually transmitted infections in the UK. new episodes seen at genitourinary medicine clinics, 1991 to 2001. London: Public Health Laboratory Service, 2002.

3 McHenry A, Evans BG, Sinka K, et al. Numbers of adults with diagnosed HIV infection 1996-2005; adjusted totals and extrapolations for England, Wales and Northern Ireland. Commun Dis Public Health 2002;5:97-100.

4 Unlinked Anonymous Surveys Steering Group. Prevalence of HIV and hepatitis infections in the United Kingdom 2001. London: Department of Health, 2002.

5 Department of Health. The national strategy for sexual health and HIV. London: DoH, 2001:1-53.

6 De Cock KM, Johnson AM. From exceptionalism to normalisation: a reappraisal of attitudes and practice around HIV testing. BMJ 1998:316:290-3.

7 Ross JD, Goldberg DJ. Patterns of HIV testing in Scotland: a general practitioner perspective. Scott Med J 1997;42:108-10.

8 Waight PA, Rush AM, Miller E. Surveillance of HIV infection by voluntary testing in England. Commun Dis Rep CDR Rev 1992;2:R85-90.

9 Mortimer PP. Ten years of laboratory diagnosis of HIV: how accurate is it now? J Antimicrob Chemother 1996;37(Suppl B):27-32.

10 PHLS, DHSS\&PS, and the Scottish ISD(D) 5 Collaborative group. Trends in sexually transmitted infections in the United Kingdom, 1990 to 2000. London: Public Health Laboratory Service, 2001

11 Department of Health. The national strategy for sexual health and HIV: implementation action plan. London: DoH, 2002.

12 Sinclair MI, Bor R, Levitt C, et al. HIV seroprevalence in a London same-day testing clinic, 2000-2001. TuPeD4958 XIV International AIDS Conference 2002.

13 Fenton KA, Chinouya M, Davidson O, et al. HIV transmission risk among subSaharan Africans in London travelling to their countries of origin. AIDS 2001;15:1442-5.

14 Fennema JS, van Ameijden EJ, Coutinho RA, et al. HIV surveillance among sexually transmitted disease clinic attenders in Amsterdam, 1991-1996. AIDS 1998; 12:931-8.

15 Schwarcz S, Kellogg T, McFarland W, et al. Differences in the temporal trends of HIV seroincidence and seroprevalence among sexually transmitted disease 
clinic patients, 1989-1998: application of the serologic testing algorithm for recent HIV seroconversion. Am J Epidemiol 2001;153:925-34.

16 Peterman TA, Zaidi AA, Wroten J. Decreasing prevalence hides a high HIV incidence: Miami. AIDS 1995;9:965-70.

17 Dukers NH, Spaargaren J, Geskus RB, et al. HIV incidence on the increase among homosexual men attending an Amsterdam sexually transmitted disease clinic: using a novel approach for detecting recent infections. AIDS 2002; 16:F19-24
18 Murphy G, Jordan LF, Charlett A, et al. Serological testing algorithm for recent HIV seroconversion shows no decline in HIV incidence in men who have sex with men attending STI clinics. AIDS (in press)

19 Gilbart VL, Evans BG, Noone A, et al. Second generation heterosexual transmission of HIV-1 infection. Commun Dis Rep 1992:2:R55-9.

20 Gupta SB, Gilbert RL, Brady AR, et al. CD4 cell counts in adults with newly diagnosed HIV infection: results of surveillance in England and Wales, 19901998. CD4 Surveillance Scheme Advisory Group. AIDS 2000;14:853-61

\section{A VIEW FROM THE SOUTH}

\section{Conference presentations (it's all a matter of timing)}
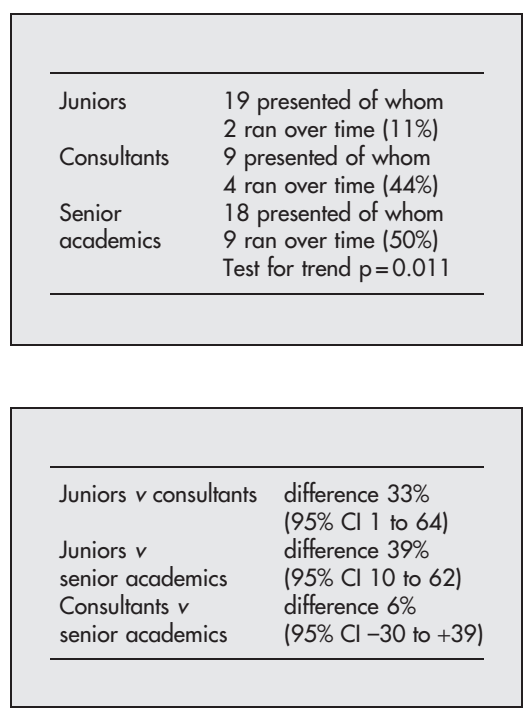

any chairs at academic meetings remind the speakers to stick to time, and it is now commonplace to hear a warning alarm as the presentation should be nearing its end. Despite this some people run over time. Theoretically, this observation should be evenly distributed among junior and senior speakers, although anecdotally this does not appear to be the case. The objective of this study was to determine the proportion of speakers who overran their allotted time, by grade of speaker.

All individuals giving an oral presentation at the Medical Society for the Study of Venereal Disease (MSSVD) annual spring meeting (2001) were included.

Each speaker was placed into one of three groups:

(1) Juniors (junior doctors, nurses, health advisers, junior scientists)

(2) Consultants

(3) Academic consultants and senior scientists (professors, senior lecturers)

A record was made of each speaker's allotted time (according to the conference programme) and the actual time spent speaking (using a stopwatch). Time given to questions was not included.

Remarks to the speakers about time keeping were noted.

The results are given in the tables

At the start of each session only juniors were reminded of the importance of sticking to time.

\section{COMMENT}

Irrespective of seniority all speakers at academic conferences should limit their presentations to their allotted times. However, both consultants and senior academics were statistically significantly more likely to run over time in their presentations when compared with juniors. There was no evidence of any difference between consultants and senior academics.

Ideally, conferences should promote through presentation and discussion the development of ideas, the ongoing progression of research, and the practical application of such research in the real world. Time is often limited by the amount of material being presented. It is one of the chair's responsibilities to keep oral presentations to time. If talks are allowed to overrun, time for other valued academic pursuits, ${ }^{1}$ discussion, and poster observations are consequently shortened.

Wiese et al, ${ }^{2}$ through a structured instruction programme, improved both the quality and efficiency of oral presentations among a group of medical undergraduates. It is probable that the results in this study are a consequence of similar preparations. Many a speaker will remember as a junior writing and rewriting their talks; and rehearsing their presentation in front of colleagues in an attempt to get it perfect for the conference.

It was also observed at this meeting that chairs reserved their warnings of time keeping and threats of interruption to junior speakers-that is, the group least likely to run over time.

As a result of this study should chairs now concentrate such words on the groups of speakers most likely to run over time?

G Rooney Sexual Health Department, Great Western Hospital, Swindon SN3 6BB, UK

Correspondence to: G Rooney; guyrooney@yahoo.com

\section{REFERENCES}

1 Tulsky A, Kouides R. Abstract presentations: what do SGIM presenters prefer? J Gen Intern Med 1998;13:417-18.

2 Wiese J, Varosy P, Tierney L. Improving oral presentation skills with a clinical reasoning curriculum: a prospective controlled study. Am J Med 2002;112:212-18. 